\title{
The search for new amphiphiles: synthesis of a modular, high-throughput library
}

\author{
George C. Feast ${ }^{1}$, Thomas Lepitre ${ }^{1}$, Xavier Mulet ${ }^{1}$, Charlotte E. Conn ${ }^{1}$, Oliver E. Hutt ${ }^{1}$, \\ G. Paul Savage*1 and Calum J. Drummond ${ }^{* 1,2}$
}

\author{
Full Research Paper \\ Address: \\ ${ }^{1}$ CSIRO Materials Science and Engineering, Bag 10, Clayton South \\ MDC, VIC 3169, Australia and ${ }^{2}$ School of Applied Sciences, College \\ of Science, Engineering and Health, RMIT University, GPO Box 2476, \\ Melbourne, VIC 3001, Australia \\ Email: \\ G. Paul Savage* - paul.savage@csiro.au; Calum J. Drummond ${ }^{*}$ - \\ calum.drummond@csiro.au \\ * Corresponding author \\ Keywords: \\ amphiphiles; carbohydrates; click chemistry; high throughput; library \\ synthesis
}

Beilstein J. Org. Chem. 2014, 10, 1578-1588.

doi:10.3762/bjoc. 10.163

Received: 28 January 2014

Accepted: 03 June 2014

Published: 10 July 2014

Associate Editor: H. Ritter

(C) 2014 Feast et al; licensee Beilstein-Institut. License and terms: see end of document.

\begin{abstract}
Amphiphilic compounds are used in a variety of applications due to their lyotropic liquid-crystalline phase formation, however only a limited number of compounds, in a potentially limitless field, are currently in use. A library of organic amphiphilic compounds was synthesised consisting of glucose, galactose, lactose, xylose and mannose head groups and double and triple-chain hydrophobic tails. A modular, high-throughput approach was developed, whereby head and tail components were conjugated using the coppercatalysed azide-alkyne cycloaddition (CuAAC) reaction. The tails were synthesised from two core alkyne-tethered intermediates, which were subsequently functionalised with hydrocarbon chains varying in length and degree of unsaturation and branching, while the five sugar head groups were selected with ranging substitution patterns and anomeric linkages. A library of 80 amphiphiles was subsequently produced, using a 24 -vial array, with the majority formed in very good to excellent yields. A preliminary assessment of the liquid-crystalline phase behaviour is also presented.
\end{abstract}

\section{Introduction}

Amphiphilic compounds contain a hydrophilic polar head group and a hydrophobic non-polar side chain. Upon addition of water, these amphiphiles may self-assemble into lyotropic phases that have a variety of uses, from simple household detergents and cleaning products, to biomedical applications including MRI imaging agents [1-3], membrane-protein crystallisation media [4-6] and solubilising bioactive food additives (Figure 1) [7]. Furthermore, recent research has centred on the use of amphiphile nanoparticles for drug-delivery applications [8-11]. 


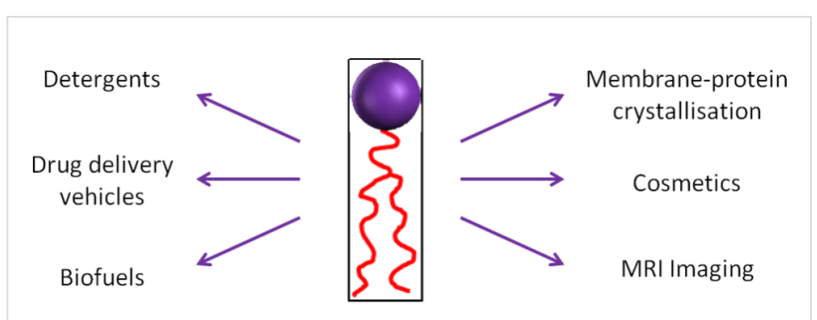

Figure 1: Examples of amphiphile applications.

Each of these applications requires a specific, stable liquid-crystalline phase. The phase behaviour can have a significant impact on performance for the end application with, for example, drugrelease rates known to vary depending on the geometrical characteristics of the lyotropic phase [12]. Increasing the lattice parameter of the liquid-crystalline phase may also facilitate the uptake of larger bioactive molecules [4].

At present, only a small selection of amphiphiles is used in the aforementioned applications. Research into the design, synthesis, and material characterisation of new amphiphiles has been underexplored, generally due to technical difficulties in the synthesis and handling of such compounds [13]. Thus, a new method combining high-throughput synthesis and liquidcrystalline phase characterisation may open new territory in the field of amphiphile discovery.

Furthermore, whilst the degree of lipophilicity, the polarity of the molecule, and the volume and shape of the molecule have all been attributed to controlling phase behaviour, the understanding of the interplay and relative contribution of these factors is still evolving. Therefore, in addition to discovering new amphiphilic species, the synthesis of a combinatorial library of amphiphilic compounds would allow the factors that drive self-assembly and liquid-crystalline phase formation to be analysed. Such studies are critical to the further development and design of new amphiphiles tailored for a specific application, and to deepen the understanding of how molecular structure influences the characteristics of self-assembly.

Previous amphiphile libraries have been prepared using a thiol-yne reaction [14] and an in situ hydrazone formation between aldehyde tails and hydrazide head groups [15] in order to study gene delivery. Many other fields have utilised the copper-catalysed azide-alkyne cycloaddition (CuAAC) 'click' reaction $[16,17]$ to generate libraries of compounds, including enzyme inhibitors [18-20], catalysis ligands [21-23] and metal frameworks $[24,25]$. We have recently demonstrated that a library of amphiphiles, with ammonium head groups and singlechain saturated tails, can be synthesised in a combinatorial approach, using this chemistry [26]. Amphiphiles and self-assem- bled nanoparticles have been synthesised using CuAAC chemistry previously [27-29], however to our knowledge, this was the first amphiphile library synthesised in this manner.

In a follow-up study, this protocol was applied to produce amphiphiles with single-chained saturated, unsaturated, and branched tails with sugar head groups [30]. This library of amphiphiles was analysed by high-throughput synchrotron small-angle X-ray scattering (SSAXS), to determine the liquidcrystalline phases of the individual compounds. These amphiphiles were found to form normal phases that have interfaces that curve away from water (Figure 2). For the majority of biomedical applications, inverse phase-forming amphiphiles (with interfaces that curve towards the aqueous domain) are desirable as they maintain the same lyotropic structure upon dilution [8].

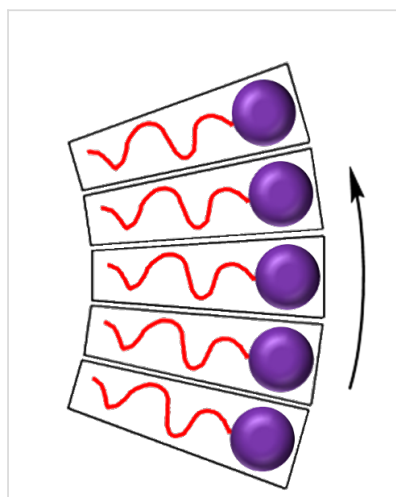

Normal phase: Curve away from water

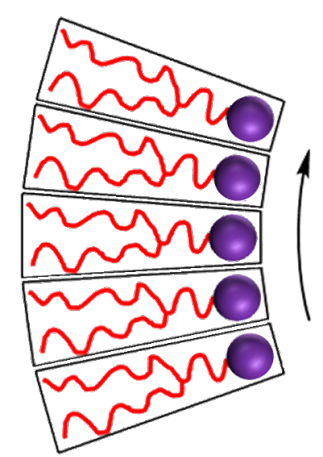

Inverse phase: Curve towards water
Figure 2: Upon self-assembly, amphiphiles pack and curve away from (normal phase) or towards (inverse phase) water.

Inverse phases typically form from amphiphiles with multiple hydrocarbon-chain tails. Therefore, to tune our amphiphiles towards inverse phase formation, we undertook the synthesis of double and triple-chain, alkyne-tethered tails, and subsequently used these to synthesise a library of multi-chained amphiphiles in a high-throughput manner.

\section{Results and Discussion}

In order to synthesise double and triple-chain tails with a variety of chain types, a synthetic route was required that enabled a late-stage, modular addition of the hydrocarbon chains; the products of which could be taken straight into the highthroughput $\mathrm{CuAAC}$ reaction.

To this end, diol 2 was synthesised by esterification of commercially available 3-hydroxy-2-(hydroxymethyl)-2-methyl- 
propanoic acid (1), according to the procedure of Whittaker et al. (Scheme 1) [31]. Diol 2 was subsequently acylated twice using a variety of long-chain carboxylic acids, and diisopropylcarbodiimide (DIC) as a coupling agent, to afford double-chain tails $\mathbf{3}-\mathbf{1 3}$ in predominantly good yields. This method avoided the need to protect the diol prior to acylation [32].

For the triple-chained tails, triol $\mathbf{1 5}$ was synthesised from tris(hydroxymethyl)methylamine (TRIS) and 4-pentynoic acid using ethoxycarbonyl-2-ethoxy-1,2-dihydroquinoline (EEDQ), following a similar method to Pucci et al. (Scheme 2) [33] TRIS has been used previously for the synthesis of amphiphilic drug-delivery vehicles, with advantages including its inexpensive availability and non-toxic nature [34,35].

Treatment of core molecule $\mathbf{1 5}$ with 3.5 equivalents of various fatty acids, using a similar coupling procedure as for the double-chain tails, gave alkynes 16-24 in moderate to good yields. Lower yields were attributed to steric hindrance of the second and third esterifications, as well as the presence of mono- and diesters making the purification more difficult. 4-Pentynoic acid was used rather than 3-butynoic acid due to the relative price and availability, as well as placing the alkyne a further methylene unit from the very bulky tertiary centre, which may have hindered the CuAAC reaction.

Using the above methods, a total of twenty tails were synthesised (11 double and 9 triple-chained, Table 1). These consisted of saturated chains with systematic ethylene increases between $\left(\mathrm{CH}_{2}\right)_{6} \mathrm{CH}_{3}$ (abbreviated to $\mathrm{C} 7$ ) and $\left(\mathrm{CH}_{2}\right)_{16} \mathrm{CH}_{3}$, as well as branched (phytanic), monounsaturated (palmitoleic, oleic and erucic) and polyunsaturated (linoleic) chains, which have been shown to promote the formation of inverse hexagonal and/or inverse bicontinuous cubic lyotropic phases in related systems [36-38].

A summary of the tail syntheses are presented in Table 1. The largest saturated tail (C17) was not synthesised as a triple chain due to the poor solubility of the product, while linoleic tails were only synthesised for double chains as the volume of a triple-chain tail would be unfavourable for lyotropic phase formation. The yields for each chain type are fairly consistent between double and triple-chain analogues, highlighting the practicality of using this modular approach. These compounds were able to go directly into the high-throughput CuAAC reactions to synthesise double and triple-chain amphiphiles.<smiles>CC(CO)(CO)C(=O)O</smiles>

1

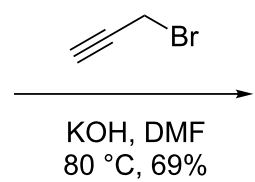

$80^{\circ} \mathrm{C}, 69 \%$<smiles>C#CCOC(=O)C(C)(CO)CO</smiles>

2

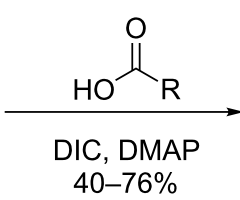

$40-76 \%$<smiles>[R]C(=O)OCC(C)(COC([R])=O)C(=O)OCC#C</smiles>

3, $\mathrm{R}=\left(\mathrm{CH}_{2}\right)_{6} \mathrm{CH}_{3}, 72 \% ; \mathbf{4}, \mathrm{R}=\left(\mathrm{CH}_{2}\right)_{8} \mathrm{CH}_{3}, 71 \% ; \mathbf{5}, \mathrm{R}=\left(\mathrm{CH}_{2}\right)_{10} \mathrm{CH}_{3}, 70 \% ; \mathbf{6}, \mathrm{R}=\left(\mathrm{CH}_{2}\right)_{12} \mathrm{CH}_{3}, 56 \% ; 7, \mathrm{R}=\left(\mathrm{CH}_{2}\right)_{14} \mathrm{CH}_{3}, 62 \%$; 8, $\mathrm{R}=\left(\mathrm{CH}_{2}\right)_{16} \mathrm{CH}_{3}, 62 \% ; 9, \mathrm{R}=\mathrm{CH}_{2} \mathrm{CH}\left(\mathrm{CH}_{3}\right)\left(\mathrm{CH}_{2} \mathrm{CH}_{2} \mathrm{CH}\left(\mathrm{CH}_{3}\right)\right)_{3} \mathrm{CH}_{3}, 52 \% ; 10, \mathrm{R}=\left(\mathrm{CH}_{2}\right)_{5} \mathrm{CH}=\mathrm{CH}\left(\mathrm{CH}_{2}\right)_{7} \mathrm{CH}_{3}, 62 \% ; 11, \mathrm{R}=$ $\left(\mathrm{CH}_{2}\right)_{7} \mathrm{CH}=\mathrm{CH}\left(\mathrm{CH}_{2}\right)_{7} \mathrm{CH}_{3}, 76 \% ; 12, \mathrm{R}=\left(\mathrm{CH}_{2}\right)_{11} \mathrm{CH}=\mathrm{CH}\left(\mathrm{CH}_{2}\right)_{7} \mathrm{CH}_{3}, 69 \% ; 13, \mathrm{R}=\left(\mathrm{CH}_{2}\right)_{7} \mathrm{CH}=\mathrm{CHCH} \mathrm{CH}_{2} \mathrm{CH}\left(\mathrm{CH}_{2}\right)_{4} \mathrm{CH}_{3}, 40 \%$.

Scheme 1: Synthesis of double-chain, alkyne-tethered tails<smiles>NC(CO)(CO)CO</smiles>

14

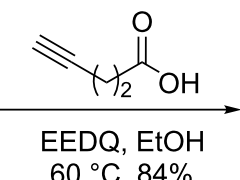

$60{ }^{\circ} \mathrm{C}, 84 \%$<smiles>C#CCCC(=O)NC(CO)(CO)CO</smiles>

15<smiles>[R]C(=O)OCC(COC([R])=O)(COC([R])=O)NC(=O)CCC#C</smiles>

16-24

16, $\mathrm{R}=\left(\mathrm{CH}_{2}\right)_{6} \mathrm{CH}_{3}, 77 \% ; 17, \mathrm{R}=\left(\mathrm{CH}_{2}\right)_{8} \mathrm{CH}_{3}, 72 \% ; 18, \mathrm{R}=\left(\mathrm{CH}_{2}\right)_{10} \mathrm{CH}_{3}, 71 \% ; \mathbf{1 9}, \mathrm{R}=\left(\mathrm{CH}_{2}\right)_{12} \mathrm{CH}_{3}, 79 \% ; 20, \mathrm{R}=\left(\mathrm{CH}_{2}\right)_{14} \mathrm{CH}_{3}$, $61 \% ; 21, \mathrm{R}=\mathrm{CH}_{2} \mathrm{CH}\left(\mathrm{CH}_{3}\right)\left(\mathrm{CH}_{2} \mathrm{CH}_{2} \mathrm{CH}\left(\mathrm{CH}_{3}\right)\right)_{3} \mathrm{CH}_{3}, 61 \% ; \mathbf{2 2}, \mathrm{R}=\left(\mathrm{CH}_{2}\right)_{5} \mathrm{CH}=\mathrm{CH}\left(\mathrm{CH}_{2}\right)_{7} \mathrm{CH}_{3}, 53 \% ; \mathbf{2 3}, \mathrm{R}=$ $\left(\mathrm{CH}_{2}\right)_{7} \mathrm{CH}=\mathrm{CH}\left(\mathrm{CH}_{2}\right)_{7} \mathrm{CH}_{3}, 63 \% ; 24, \mathrm{R}=\left(\mathrm{CH}_{2}\right)_{11} \mathrm{CH}=\mathrm{CH}\left(\mathrm{CH}_{2}\right)_{7} \mathrm{CH}_{3}, 70 \%$. 


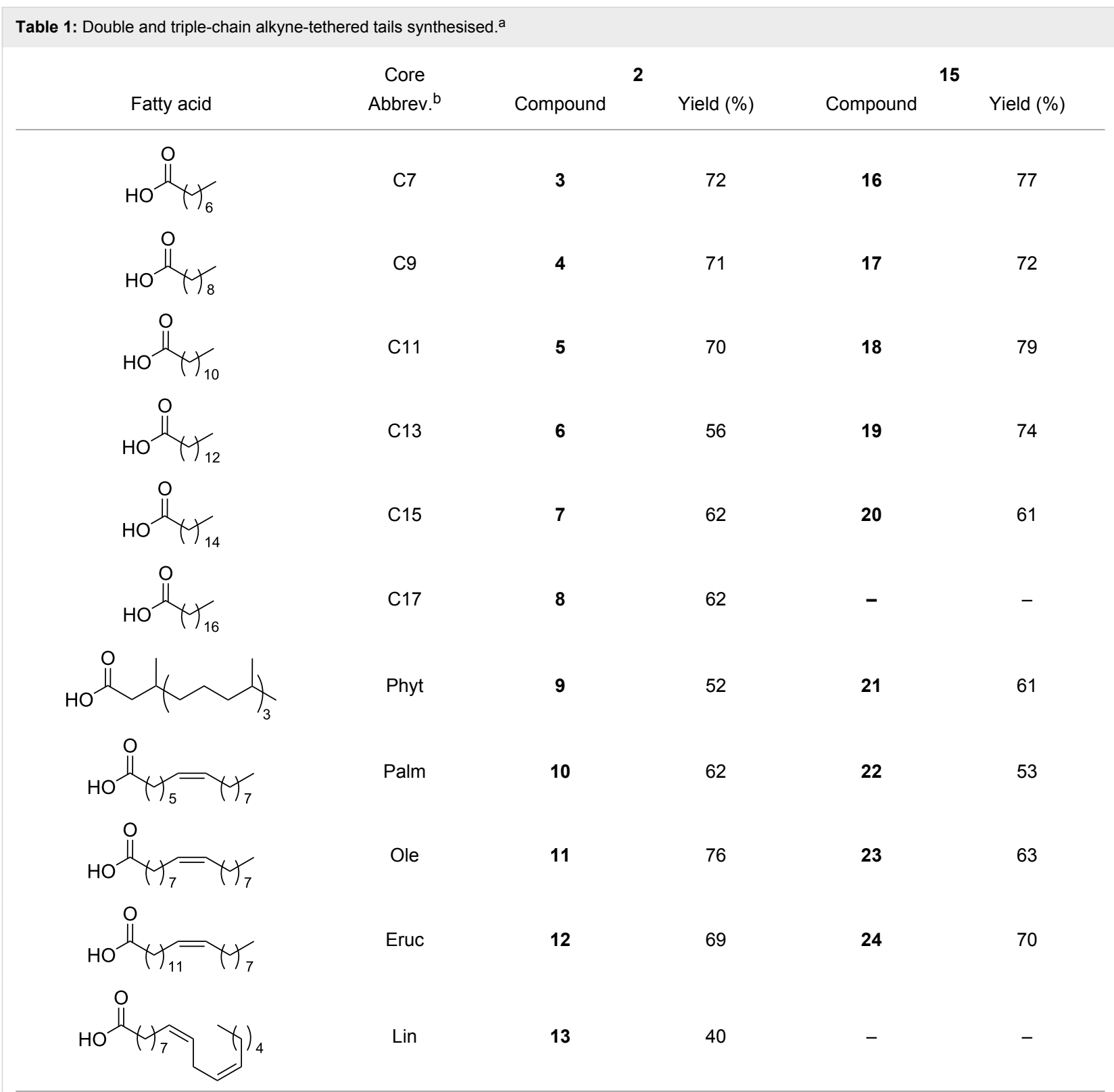

${ }^{\mathrm{a}} \mathrm{A}$ dash indicates those not synthesised. ${ }^{\mathrm{b}} \mathrm{Phyt}=$ phytanic, Palm $=$ palmitoleic, Ole $=$ oleic, Eruc $=$ erucic and Lin $=$ linoleic.

With tails in hand, attention was turned to the hydrophilic amphiphile head groups. Sugar head groups were selected for this library because sugars are popular drug targets; however, such compounds often suffer from poor bioavailability [39]. By loading such drugs as amphiphilic assemblies, sugar recognition and subsequent excretion should be reduced [40-42]. Sugar-based amphiphiles are often termed glycolipids and are also of interest for their use as 'green' surfactants in household cleaning products [43]. Previous work in this field has been extensively reviewed [44-50]. Azido-sugars are known to react well under $\mathrm{CuAAC}$ reaction conditions [51,52] and have recently been used in the synthesis of a glycodendrimer library
[53], as well as in our previous work on single-chain sugar amphiphiles [30]. Hence, a diverse sugar screen would provide a wealth of data on the appropriate characteristics for a selfassembled sugar-based amphiphilic drug.

Five sugars were chosen for this library: glucose, galactose, lactose, xylose and mannose. Glucose and galactose amphiphiles have been demonstrated to possess slightly different lyotropic phase behaviour, despite the relatively small structural difference (epimers) between the two monosaccharides. Xylose does not bear the 6-position side-chain alcohol so it takes up a significantly smaller volume. Lactose is a disaccha- 
ride so it has a much larger head-group volume. The four azidosugars associated with these sugars are linked through a $\beta$-anomeric linkage, therefore an $\alpha$-linked mannose was also selected for comparison (Figure 3).

These azido-sugars were commercially available with the exception of azido-xylose $\mathbf{2 7}$, which was synthesised in three steps from the parent sugar using trimethylsilylazide and iron(III) chloride (Scheme 3) [54]. The $\beta$-configuration of the azide was confirmed by comparison of coupling constants with literature data [55].<smiles>OC1CC2OC(COC2O)OC1O</smiles>

30

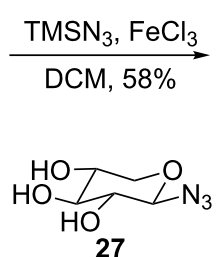

Scheme 3: Synthesis of azido-xylose.

With both head groups and tails in hand, high-throughput CuAAC reactions were employed to synthesise amphiphiles using a 24-vial array. Azido-sugars were dissolved in a mixture of tert-butanol and water in $2 \mathrm{~mL}$ glass vials, followed by the addition of the alkyne tails (Figure 4). These were heated to $40{ }^{\circ} \mathrm{C}$ to dissolve the alkyne, before the addition of copper powder. After stirring for $24 \mathrm{~h}$ ( $48 \mathrm{~h}$ for mannose compounds), the reaction mixtures were filtered into vials using a multi-tap vacuum chamber (Figure 5) and the solutions evaporated to dryness simultaneously, using a vacuum centrifuge, to yield 24 amphiphiles.

This process was repeated to yield 80 novel amphiphiles, 46 with double-chain tails and 34 with triple-chain tails. The yields for the double-chain amphiphiles are presented in Table 2.

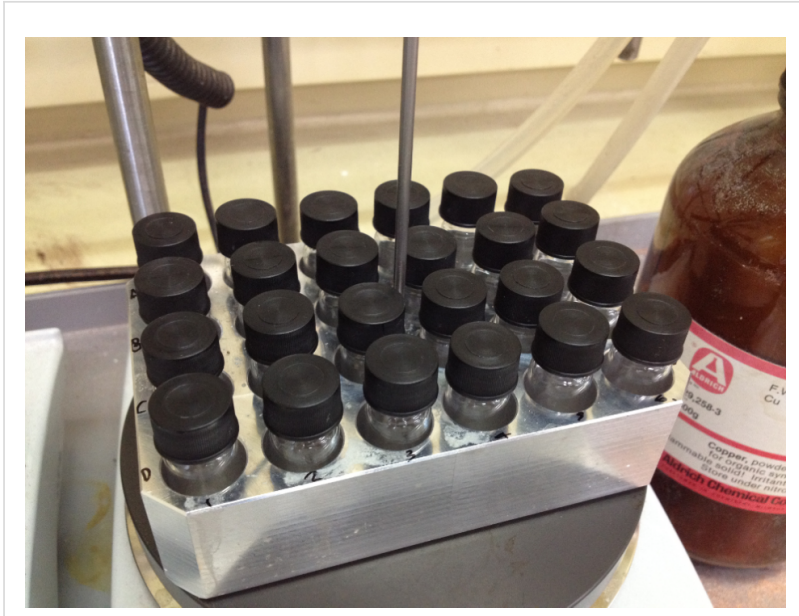

Figure 4: 24-vial array set up.

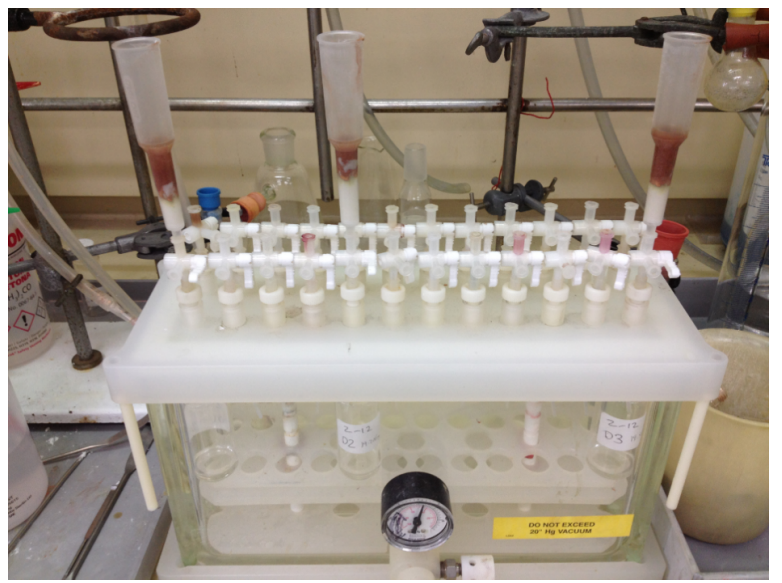

Figure 5: Multi-tap vacuum chamber for high-throughput filtering.

Almost all compounds were synthesised in very good to excellent yields. The yields were consistent both in terms of the sugar head group and the length and nature of the tail, emphasising the synthetic utility of this route towards amphiphile synthesis. Only for the longest of the saturated chains (C17) was a moderate yield observed; a ${ }^{1} \mathrm{H}$ NMR sample of the galactose amphiphile 47 proved difficult to prepare (due to poor solu-

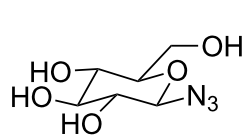

25

$\beta$-azido-glucose<smiles>O=C1OC(O)C(O)C(O)[C@H]1CO</smiles>

26

$\beta$-azido-galactose

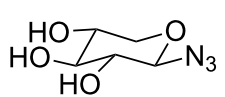

27

$\beta$-azido-xylose<smiles>OCC(O)C1OCOC1O</smiles>

28

$\alpha$-azido-mannose

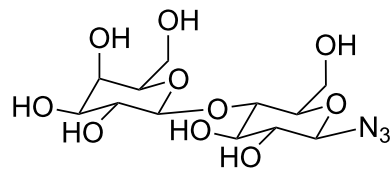

29

$\beta$-azido-lactose

Figure 3: Azido-sugar head groups used in library. 
Table 2: Synthesis of double-chained amphiphiles. ${ }^{a}$<smiles>[R]C1OC([N])C(O)C(O)C1[R6]</smiles>

25-29<smiles>[R7]C(=O)OCC(C)(COC([R7])=O)C(=O)OCC#C</smiles>

3-13<smiles>[R7]C(=O)OCC(C)(COC([R7])=O)C(=O)OCc1cn(C2OC([R])C([R20])C(O)C2O)nn1</smiles>

33-78

\begin{tabular}{|c|c|c|c|c|c|c|c|c|c|c|}
\hline \multirow{2}{*}{$\begin{array}{c}\text { Sugar } \\
\text { Tail (R") }\end{array}$} & \multicolumn{2}{|c|}{ Glucose } & \multicolumn{2}{|c|}{ Galactose } & \multicolumn{2}{|c|}{ Xylose } & \multicolumn{2}{|c|}{ Mannose } & \multicolumn{2}{|c|}{ Lactose } \\
\hline & Comp. & Yield (\%) & Comp. & Yield (\%) & Comp. & Yield (\%) & Comp. & Yield (\%) & Comp. & Yield (\%) \\
\hline $\mathrm{C} 7$ & 33 & 92 & 42 & 90 & 53 & 93 & 64 & 87 & 70 & 89 \\
\hline $\mathrm{Cg}$ & 34 & 90 & 43 & 86 & 54 & 88 & 65 & 85 & 71 & 92 \\
\hline C11 & 35 & 89 & 44 & 88 & 55 & 86 & 66 & 68 & 72 & 94 \\
\hline C13 & 36 & 85 & 45 & 88 & 56 & 92 & \multicolumn{2}{|c|}{$x$} & 73 & 88 \\
\hline C15 & \multicolumn{2}{|c|}{-} & 46 & 80 & 57 & 94 & \multicolumn{2}{|c|}{-} & \multicolumn{2}{|c|}{-} \\
\hline C17 & \multicolumn{2}{|c|}{-} & 47 & 60 & 58 & 65 & \multicolumn{2}{|c|}{-} & \multicolumn{2}{|c|}{-} \\
\hline Phyt & 37 & 88 & 48 & 91 & 59 & 87 & 67 & 82 & 74 & 78 \\
\hline Palm & 38 & 90 & 49 & 87 & 60 & 88 & 68 & 82 & 75 & 80 \\
\hline Ole & 39 & 85 & 50 & 78 & 61 & 81 & 69 & 76 & 76 & 74 \\
\hline Eruc & 40 & 76 & 51 & 86 & 62 & 70 & \multicolumn{2}{|c|}{$x$} & 77 & 84 \\
\hline Lin & 41 & 82 & 52 & 96 & 63 & 96 & \multicolumn{2}{|c|}{$x$} & 78 & 92 \\
\hline
\end{tabular}

aDashes indicate those not attempted, $\mathrm{x}$ indicates those which did not reach completion. Tail abbreviations are found in Table 1.

bility) and the presence of unreacted azido-sugar was prevalent in the spectrum. The lower yield was therefore attributed to the poor solubility of the tails in the butanol/water solvent combination and thus the longest saturated chain (C15 and C17) amphiphiles were only synthesised from galactose and xylose.

Comparable yields were observed for the $\beta$-linked head groups for the short-chain saturated tails and the phytanic, palmitoleic and oleic tails. However the mannose reactions of chains longer than $\mathrm{C} 11$ and oleic were unable to reach completion, which was attributed to the $\alpha$-linkage of the azide at the anomeric centre, creating steric hindrance for the $[3+2]$ cycloaddition.

The yields for triple-chain amphiphiles are presented in Table 3. For the three saturated chains (C7, C9 and C11), excellent yields were obtained for most head groups, with good yields observed for the sterically-demanding $\alpha$-linked mannose. For the phytanyl-chained amphiphiles moderate to very good yields were observed. This decrease in yield, attributed to increased steric interactions, was also observed for the longer chain erucic compounds, although these may also have suffered from poor solvation. ${ }^{1} \mathrm{H}$ NMR of an example phytanyl compound 96 showed the presence of azido-xylose starting material, confirming that the reaction did not proceed to completion. Attempts to synthesise amphiphiles using the C13 (19) and C15 (20) triple-chain tails failed, as these compounds did not dissolve readily under the library synthesis reactions conditions.

When comparing double and triple-chain amphiphiles, the results are similar. Excellent yields are observed for all $\mathrm{C} 7$ and C9-chained tails, with the exception of triple-chained $\alpha$-linked mannose. A noticeable difference is observed, however, when comparing the yields of the phytanyl-chained amphiphiles; the triple chains exhibit yields $10-30 \%$ lower than for their doublechain analogues. It is reasonable to attribute this decrease to the increased steric demands of the branched chains. Both palmitoleic and oleic chain yields are reasonably consistent between double and triple, while a reduction in yield is observed for the very long erucic chains for the triple analogues.

The purity of the compounds was determined by ${ }^{13} \mathrm{C}$ NMR and mass spectrometry. Since individual NMR analysis was impractical for such a large library, a random selection of 15 amphiphiles underwent ${ }^{13} \mathrm{C}$ NMR spectroscopy representing three of each type of sugar and covering a range of double and triple tails. These spectra were found mostly to be of very good quality, with only minor amounts of starting material present in some samples (see data and spectra in Supporting Information File 1, S22-S32). Only one sample (triple-chain lactose amphiphile 106) was found to contain significant amounts of tail starting material. It is postulated that a longer reaction time 
Table 3: Synthesis of triple-chained amphiphiles. ${ }^{a}$<smiles>[R7]C(=O)OCC(COC([R])=O)(COC([R])=O)NC(=O)CCc1cn(C2OC([R])C([R])C(O)C2O)nn1</smiles>

\begin{tabular}{|c|c|c|c|c|c|c|c|c|c|c|}
\hline \multirow{2}{*}{$\begin{array}{l}\text { Sugar } \\
\text { Tail (R") }\end{array}$} & \multicolumn{2}{|c|}{ Glucose } & \multicolumn{2}{|c|}{ Galactose } & \multicolumn{2}{|c|}{ Xylose } & \multicolumn{2}{|c|}{ Mannose } & \multicolumn{2}{|c|}{ Lactose } \\
\hline & Comp. & Yield (\%) & Comp. & Yield (\%) & Comp. & Yield (\%) & Comp. & Yield (\%) & Comp. & Yield (\%) \\
\hline $\mathrm{C} 7$ & 79 & 89 & 86 & 95 & 93 & 96 & 100 & 71 & 106 & 88 \\
\hline $\mathrm{C9}$ & 80 & 98 & 87 & 95 & 94 & 99 & 101 & 61 & 107 & 96 \\
\hline C11 & 81 & 89 & 88 & 93 & 95 & 85 & 102 & 73 & 108 & 92 \\
\hline Phyt & 82 & 79 & 89 & 69 & 96 & 63 & 103 & 52 & 109 & 68 \\
\hline Palm & 83 & 89 & 90 & 81 & 97 & 89 & 104 & 96 & 110 & 79 \\
\hline Ole & 84 & 91 & 91 & 89 & 98 & 78 & 105 & 82 & 111 & 69 \\
\hline Eruc & 85 & 60 & 92 & 50 & 99 & 69 & & $x$ & 112 & 53 \\
\hline
\end{tabular}

${ }^{a} \mathbf{x}$ indicates those which did not reach completion. Tail abbreviations are found in Table 1.

would have allowed complete conversion of the two bulky reactants into product.

All amphiphiles were subjected to MALDI-TOF mass spectrometry to determine product formation, and of the 80 amphiphiles in the library, only $3(4 \%)$ did not generate the desired mass unit (Supporting Information File 1, Table S1).

In order to determine the purity of the compounds with regard to residual copper, inductively coupled plasma mass spectrometry (ICP-MS) was performed on three random samples (since a large amount of material is required for this technique). The results are presented in Table 4.

Table 4: Copper content analysis of amphiphiles. ${ }^{a}$

\begin{tabular}{lcc} 
Amphiphile & \multicolumn{2}{c}{${ }^{63} \mathrm{Cu}$ content (ppm) } \\
\hline Galactose-2 × Phyt & 48 & 20 \\
Glucose-3 × C7 & 79 & 550 \\
Lactose-3 x C9 & 107 & 80
\end{tabular}

Tail abbreviations are found in Table 1.

All three compounds had copper contents $<0.06 \%$ and, when combined with the ${ }^{13} \mathrm{C}$ NMR and MALDI-TOF data, we were satisfied the compounds were pure enough for subsequent lyotropic phase data to be of significance in the context of a screen.
The amphiphiles produced in this library are tailored to preferentially form inverse phases due to the large chain volume of the double and triple chains (Figure 2). Variations in the degree of curvature upon amphiphile packing lead to different individual phases [56-58]. As the propensity for curvature increases, the phase transitions are often lamellar $\rightarrow$ cubic $\rightarrow$ hexagonal $\rightarrow$ micellar [36]. An assessment of the phase behaviour of some amphiphiles was undertaken using cross-polarised microscopy. Each type of phase exhibits a distinct optical texture under the influence of polarised light [59]. Three compounds were chosen with different head groups (glucose, xylose and lactose) but the same double-chain tail (C7). The samples were placed between a microscope slide and a cover slip before flooding with water. The phase at the water-amphiphile interface was then observed (Figure 6).

The images A and B show an isotropic phase at the water-amphiphile boundary (confirmed by a dark image when viewed with crossed polarisers) indicating the presence of either a cubic or micellar phase. By contrast the lactose amphiphile $\mathbf{7 0}$ (Figure 7) shows a birefringent texture corresponding to a lamellar phase. Preliminary small-angle X-ray scattering data for these amphiphiles at high water concentrations match these assignments, with glucose amphiphile $\mathbf{3 3}$ exhibiting a gyroid inverse cubic phase, and xylose amphiphile 53 exhibiting an inverse micellar phase, at $25{ }^{\circ} \mathrm{C}$. This clearly follows the expected pattern of increasing curvature with decreasing head group size (Figure 7). A disaccharide, such as lactose, has a large volume; however, in this amphiphilic form, the volume of 

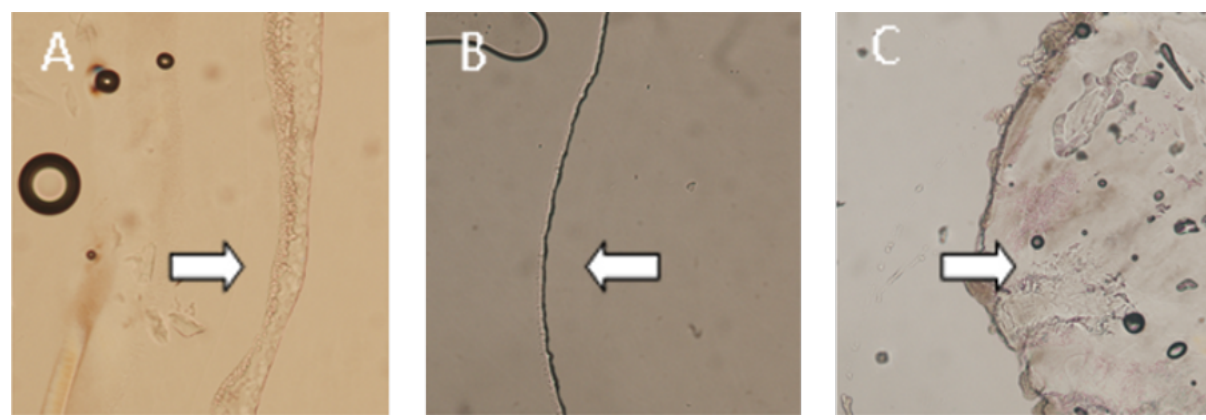

Figure 6: Cross-polarised microscopy of (A) glucose $2 \times C 7,33,(B)$ xylose $2 \times C 7,53$, and (C) lactose $2 \times C 7,70$ amphiphiles under excess water conditions at $25^{\circ} \mathrm{C}$. The arrows indicate the phase at the water-amphiphile boundary.

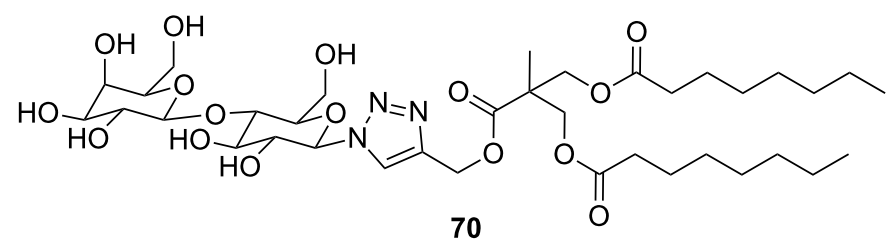
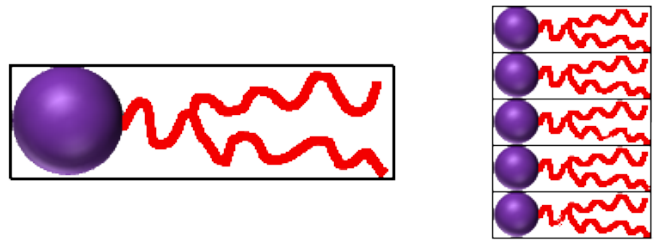<smiles>CCCCCCCCCCCC(=O)OCC(C)(COC(=O)COCc1cn(CCO)nn1)C(=O)O</smiles>
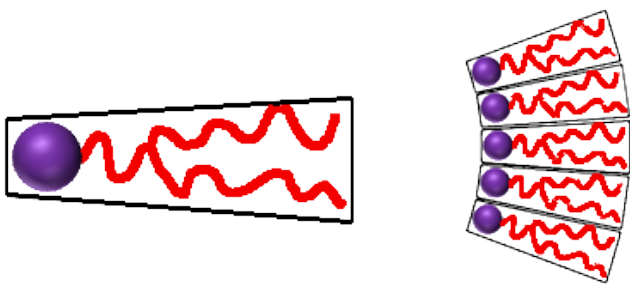<smiles>CCCCCCCCCCC(=O)OCC(C)(COC(=O)COCc1cn(CCO)nn1)C(=O)O</smiles>
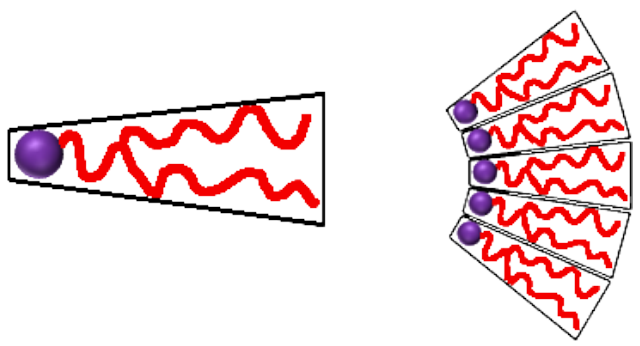

Figure 7: Differences in head group volume lead to differences in the curvature (and thus liquid-crystalline phase) of the self-assembled material.

the head group is matched by the volume of the double hydrocarbon chains and therefore, in water, the compound assembles into a lamellar phase. Upon reducing the head group size to glucose, we obtain a wedge-like amphiphile that curves towards water to give a material that self-assembles into an inverse cubic phase. Decreasing the head group size further to xylose, results in the formation of a highly curved inverse micellar phase.

When we combine these results with those from our singlechain amphiphile library (that form normal phases) [30], we are able to achieve lyotropic phases ranging across the structural landscape of normal to inverse micelles. Upon completion of the comprehensive phase behaviour analysis of this second library, using high-throughput small-angle X-ray scattering (SAXS) at the Australian Synchrotron, we predict that amphiphiles will be found of various inverse phases, thus creating a template from which novel amphiphiles can be synthetically designed for a specific end application.

\section{Conclusion}

A library of double and triple-chained amphiphiles was synthesised using a modular, high-throughput approach. The compounds have systematic variations in chain length, splay and 
head-group size in order to gain knowledge of the relationship between molecular structure, and the structure of the selfassembled form of the amphiphile. The core molecules synthesised in this modular approach are highly adaptable and could be used to make double and triple-chained tails with differing chains on each arm. A preliminary investigation of three amphiphiles with various sized sugar head groups confirms that by decreasing the volume of the head group we are increasing the curvature at the amphiphile-water interface and thus move towards desired inverse phase formation.

\section{Experimental}

General procedure for the synthesis of amphiphiles. To each of 24 glass vials $(18 \mathrm{~mm} \times 45 \mathrm{~mm})$ in a $4 \times 6$ array aluminium reaction block, was added a solution of azido-sugar (1.0 equiv, ca. $15 \mathrm{mg}$ ) in $2: 1 \mathrm{t}$-BuOH/water $(1.5 \mathrm{~mL})$. Alkyne (1.0 equiv) was added and the reaction block heated with stirring, to $40{ }^{\circ} \mathrm{C}$. After dissolution, copper powder (ca. $150 \mathrm{mg}$ ) was added and the reaction stirred for $24-48 \mathrm{~h}$. The reaction mixture was cooled, diluted with ethanol $(2 \mathrm{~mL})$ and filtered through Celite ${ }^{\circledR}$ into 24 glass vials $(25 \mathrm{~mm} \times 75 \mathrm{~mm})$. Concentration in vacuo on a Genevac EZ-2, followed by vacuum oven drying $\left(50{ }^{\circ} \mathrm{C}\right.$, $3 \mathrm{~h}$ ), afforded the amphiphile products.

Cross-polarised microscopy. A small amount of neat amphiphile was placed onto a microscope slide and a cover slip placed over gently pressing to form a watertight layer of amphiphile prior to hydration of the material. The microscope slide was placed into a Linkam PE94 hot stage (Linkam Scientific Instruments Ltd.; Surrey, England) and a water drop added at the side of the cover slip to flood the sample and create a concentration gradient as water was absorbed. The interaction of water and the amphiphile was observed with a Nikon Eclipse $80 \mathrm{i}$ inverted microscope (Coherent Scientific, Melbourne) without and with an analyser. Images were captured with a Nikon DS-Fil camera (Coherent Scientific, Melbourne).

\section{Supporting Information}

\section{Supporting Information File 1}

Experimental procedures, chemical characterisation data (including ${ }^{13} \mathrm{C}$ NMR spectra) and preliminary SAXS analysis.

[http://www.beilstein-journals.org/bjoc/content/ supplementary/1860-5397-10-163-S1.pdf]

\section{Acknowledgements}

The authors would like to acknowledge Donald Thomas and Douglas Lawes, of the NMR facility within the Mark Wainwright Analytical Centre at the University of New South Wales, and Roger Mulder and Jo Cosgriff at the Ian Wark Laboratory at CSIRO, for NMR support. The authors would like to thank Carl Braybrook and Chris Sheedy at CSIRO for mass spectrometry support.

\section{References}

1. Muir, B. W.; Acharya, D. P.; Kennedy, D. F.; Mulet, X.; Evans, R. A.; Pereira, S. M.; Wark, K. L.; Boyd, B. J.; Nguyen, T.-H.; Hinton, T. M.; Waddington, L. J.; Kirby, N.; Wright, D. K.; Wang, H. X.; Egan, G. F.; Moffat, B. A. Biomaterials 2012, 33, 2723-2733. doi:10.1016/j.biomaterials.2011.12.018

2. Moghaddam, M. J.; de Campo, L.; Waddington, L. J.; Weerawardena, A.; Kirby, N.; Drummond, C. J. Soft Matter 2011, 7, 10994-11005. doi:10.1039/c1sm05957b

3. Mulder, W. J. M.; Strijkers, G. J.; van Tilborg, G. A. F.; Griffioen, A. W.; Nicolay, K. NMR Biomed. 2006, 19, 142-164. doi:10.1002/nbm.1011

4. Conn, C. E.; Drummond, C. J. Soft Matter 2013, 9, 3449-3464. doi:10.1039/c3sm27743g

5. Chae, P. S.; Rana, R. R.; Gotfryd, K.; Rasmussen, S. G. F.; Kruse, A. C.; Cho, K. H.; Capaldi, S.; Carlsson, E.; Kobilka, B.; Loland, C. J.; Gether, U.; Banerjee, S.; Byrne, B.; Lee, J. K.; Gellman, S. H. Chem. Commun. 2013, 49, 2287-2289. doi:10.1039/c2cc36844g

6. Conn, C. E.; Darmanin, C.; Mulet, X.; Hawley, A.; Drummond, C. J. Soft Matter 2012, 8, 6884-6896. doi:10.1039/c2sm25705j

7. Amar-Yuli, I.; Libster, D.; Aserin, A.; Garti, N. Curr. Opin. Colloid Interface Sci. 2009, 14, 21-32. doi:10.1016/j.cocis.2008.02.001

8. Mulet, X.; Boyd, B. J.; Drummond, C. J. J. Colloid Interface Sci. 2013, 393, 1-20. doi:10.1016/j.jcis.2012.10.014

9. Negrini, R.; Mezzenga, R. Langmuir 2011, 27, 5296-5303. doi:10.1021/la200591u

10. Fong, W.-K.; Hanley, T. L.; Thierry, B.; Kirby, N.; Boyd, B. J. Langmuir 2010, 26, 6136-6139. doi:10.1021/la100644s

11. Jiang, Y.; Luan, Y.; Qin, F.; Zhao, L.; Li, Z. RSC Adv. 2012, 2, 6905-6912. doi:10.1039/c2ra20653f

12. Phan, S.; Fong, W.-K.; Kirby, N.; Hanley, T.; Boyd, B. J. Int. J. Pharm. 2011, 421, 176-182. doi:10.1016/j.ijpharm.2011.09.022

13. Mulet, X.; Conn, C. E.; Fong, C.; Kennedy, D. F.; Moghaddam, M. J.; Drummond, C. J. Acc. Chem. Res. 2013, 46, 1497-1505. doi:10.1021/ar300285u

14. Li, L.; Zahner, D.; Su, Y.; Gruen, C.; Davidson, G.; Levkin, P. A. Biomaterials 2012, 33, 8160-8166. doi:10.1016/j.biomaterials.2012.07.044

15. Gehin, C.; Montenegro, J.; Bang, E.-K.; Cajaraville, A.; Takayama, S.; Hirose, H.; Futaki, S.; Matile, S.; Riezman, H. J. Am. Chem. Soc. 2013, 135, 9295-9298. doi:10.1021/ja404153m

16. Rostovtsev, V. V.; Green, L. G.; Fokin, V. V.; Sharpless, K. B. Angew. Chem., Int. Ed. 2002, 41, 2596-2599. doi:10.1002/1521-3773(20020715)41:14<2596::AID-ANIE2596>3.0.CO ;2-4

17. Tornøe, C. W.; Christensen, C.; Meldal, M. J. Org. Chem. 2002, 67, 3057-3064. doi:10.1021/jo011148j

18. Suzuki, T.; Ota, Y.; Ri, M.; Bando, M.; Gotoh, A.; Itoh, Y.; Tsumoto, H.; Tatum, P. R.; Mizukami, T.; Nakagawa, H.; lida, S.; Ueda, R.; Shirahige, K.; Miyata, N. J. Med. Chem. 2012, 55, 9562-9575. doi:10.1021/jm300837y

19. Irie, T.; Fujii, I.; Sawa, M. Bioorg. Med. Chem. Lett. 2012, 22, 591-596. doi:10.1016/j.bmcl.2011.10.076 
20. He, X.-P.; Xie, J.; Tang, Y.; Li, J.; Chen, G.-R. Curr. Med. Chem. 2012, 19, 2399-2405. doi:10.2174/092986712800269245

21. Dolhem, F.; Johansson, M. J.; Antonsson, T.; Kann, N J. Comb. Chem. 2007, 9, 477-486. doi:10.1021/cc0601635

22. Zhang, Q.; Takacs, J. M. Org. Lett. 2008, 10, 545-548. doi:10.1021/ol702890s

23. Struthers, H.; Mindt, T. L.; Schibli, R. Dalton Trans. 2010, 39, 675-696. doi:10.1039/b912608b

24. Savonnet, M.; Kockrick, E.; Camarata, A.; Bazer-Bachi, D.; Bats, N.; Lecocq, V.; Pinel, C.; Farrusseng, D. New J. Chem. 2011, 35, 1892-1897. doi:10.1039/c1nj20350a

25. Crowley, J. D.; Bandeen, P. H. Dalton Trans. 2010, 39, 612-623. doi:10.1039/b911276f

26. Hutt, O. E.; Mulet, X.; Savage, G. P. ACS Comb. Sci. 2012, 14, 565-569. doi:10.1021/co300080g

27. Nicolas, J.; Bensaid, F.; Desmaële, D.; Grogna, M.; Detrembleur, C.; Andrieux, K.; Couvreur, P. Macromolecules 2008, 41, 8418-8428. doi:10.1021/ma8013349

28. de Medeiros Modolon, S.; Otsuka, I.; Fort, S.; Minatti, E.; Borsali, R.; Halila, S. Biomacromolecules 2012, 13, 1129-1135. doi:10.1021/bm3000138

29. Clemente, M. J.; Fitremann, J.; Mauzac, M.; Serrano, J. L.; Oriol, L. Langmuir 2011, 27, 15236-15247. doi:10.1021/la203447e

30. Feast, G. C.; Hutt, O. E.; Mulet, X.; Conn, C. E.; Drummond, C. J.; Savage, G. P. Chem.-Eur. J. 2014, 20, 2783-2792. doi:10.1002/chem.201303514

31. Truong, V.; Blakey, I.; Whittaker, A. K. Biomacromolecules 2012, 13, 4012-4021. doi:10.1021/bm3012924

32. Li, L.; He, C.; He, W.; Wu, C. Macromolecules 2011, 44, 8195-8206. doi:10.1021/ma201687s

33. Abla, M.; Durand, G.; Pucci, B. J. Org. Chem. 2011, 76, 2084-2093. doi:10.1021/jo102245c

34. Davey, R. A.; Davey, M. W.; Cullen, K. V.; Wells, X. E.; Francis, C. L.; Williams, H.-M.; Yang, Q.; Moghaddam, M. J.; Widmer, F.; Whittaker, R. G. Br. J. Pharmacol. 2002, 137, 1280-1286. doi:10.1038/sj.bjp.0704983

35. Son, S. J.; Brimble, M. A.; Yang, S.; Harris, P. W. R.; Reddingius, T.; Muir, B. W.; Hutt, O. E.; Waddington, L.; Guan, J.; Savage, G. P. Aust. J. Chem. 2013, 66, 23-29. doi:10.1071/CH12347

36. Fong, C.; Le, T.; Drummond, C. J. Chem. Soc. Rev. 2012, 41 , 1297-1322. doi:10.1039/c1cs15148g

37. Barauskas, J.; Landh, T. Langmuir 2003, 19, 9562-9565. doi:10.1021/la0350812

38. Conn, C. E.; Panchagnula, V.; Weerawardena, A.; Waddington, L. J.; Kennedy, D. F.; Drummond, C. J. Langmuir 2010, 26, 6240-6249. doi:10.1021/la904006q

39. Ernst, B.; Magnani, J. L. Nat. Rev. Drug Discovery 2009, 8, 661-677. doi:10.1038/nrd2852

40. Park, J.; Rader, L. H.; Thomas, G. B.; Danoff, E. J.; English, D. S.; DeShong, P. Soft Matter 2008, 4, 1916-1921. doi:10.1039/b806059b

41. Aripin, N. F. K.; Park, J. W.; Park, H. J. Colloids Surf., B 2012, 95, 144-153. doi:10.1016/j.colsurfb.2012.02.032

42. Hartley, P. G.; Alderton, M. R.; Dawson, R. M.; Wells, D. Bioconjugate Chem. 2007, 18, 152-159. doi:10.1021/bc060216b

43. von Rybinski, W.; Hill, K. Angew. Chem., Int. Ed. 1998, 37, 1328-1345. doi:10.1002/(SICI)1521-3773(19980605)37:10<1328::AID-ANIE1328>3 .0.CO;2-9

44. Jayaraman, N.; Maiti, K.; Naresh, K. Chem. Soc. Rev. 2013, 42, 4640-4656. doi:10.1039/c3cs00001j
45. Hashim, R.; Sugimura, A.; Minamikawa, H.; Heidelberg, T. Liq. Cryst. 2012, 39, 1-17. doi:10.1080/02678292.2011.614017

46. Baker, I. J. A.; Drummond, C. J.; Furlong, D. N.; Grieser, F. Surfactant Biodegradation: Sugar-Based Surfactants Compared to Other Surfactants. In Handbook of Detergents: Part F - Environmental Impact; Zoller, U., Ed.; Marcel Dekker, Inc.: New York, 2004; pp 739-760.

47. Jeffrey, G. A.; Wingert, L. M. Liq. Cryst. 1992, 12, 179-202. doi:10.1080/02678299208030392

48. Goodby, J. W.; Görtz, V.; Cowling, S. J.; Mackenzie, G.; Martin, P.; Plusquellec, D.; Benvegnu, T.; Boullanger, P.; Lafont, D.; Queneau, Y.; Chambert, S.; Fitremann, J. Chem. Soc. Rev. 2007, 36, 1971-2032. doi:10.1039/b708458g

49. Goodby, J. W. Liq. Cryst. 1998, 24, 25-38. doi:10.1080/026782998207550

50. van Doren, H. A.; Smits, E.; Pestman, J. M.; Engberts, J. B. F. N.; Kellogg, R. M. Chem. Soc. Rev. 2000, 29, 183-199. doi:10.1039/a804242j

51. Wilkinson, B. L.; Bornaghi, L. F.; Houston, T. A.; Poulson, S.-A. Click Chemistry in Carbohydrate Based Drug Development and Glycobiology. In Drug Design Research Perspectives; Kaplan, S. K., Ed.; Nova Science Publishers: New York, 2007; pp 57-102.

52. Kushwaha, D.; Dwivedi, P.; Kuanar, S. K.; Tiwari, V. K. Curr. Org. Synth. 2013, 10, 90-135. doi:10.2174/1570179411310010005

53. Percec, V.; Leowanawat, P.; Sun, H.-J.; Kulikov, O.; Nusbaum, C. D.; Tran, T. M.; Bertin, A.; Wilson, D. A.; Peterca, M.; Zhang, S.; Kamat, N. P.; Vargo, K.; Moock, D.; Johnston, E. D.; Hammer, D. A.; Pochan, D. J.; Chen, Y.; Chabre, Y. M.; Shiao, T. C.;

Bergeron-Brlek, M.; André, S.; Roy, R.; Gabius, H.-J.; Heiney, P. A. J. Am. Chem. Soc. 2013, 135, 9055-9077. doi:10.1021/ja403323y

54. Salunke, S. B.; Babu, N. S.; Chen, C.-T. Chem. Commun. 2011, 47, 10440-10442. doi:10.1039/c1cc13370e

55. Bravman, T.; Belakhov, V.; Solomon, D.; Shoham, G.; Henrissat, B.; Baasov, T.; Shoham, Y. J. Biol. Chem. 2003, 278, 26742-26749. doi:10.1074/jbc.M304144200

56. Ringsdorf, H.; Schlarb, B.; Venzmer, J. Angew. Chem., Int. Ed. Engl. 1988, 27, 113-158. doi:10.1002/anie.198801131

57. Tschierske, C. Prog. Polym. Sci. 1996, 21, 775-852. doi:10.1016/S0079-6700(96)00014-7

58. Donnio, B. Curr. Opin. Colloid Interface Sci. 2002, 7, 371-394. doi:10.1016/S1359-0294(02)00084-5

59. Rosevear, F. B. J. Am. Oil Chem. Soc. 1954, 31, 628-639. doi:10.1007/BF02545595 


\section{License and Terms}

This is an Open Access article under the terms of the Creative Commons Attribution License

(http://creativecommons.org/licenses/by/2.0), which permits unrestricted use, distribution, and reproduction in any medium, provided the original work is properly cited.

The license is subject to the Beilstein Journal of Organic Chemistry terms and conditions:

(http://www.beilstein-journals.org/bjoc)

The definitive version of this article is the electronic one which can be found at:

doi:10.3762/bjoc. 10.163 